Revista Iberoamericana. Vol. LXVI, Núm. 192, Julio-Septiembre 2000, 533-544

\title{
ATRACCIÓN Y REPULSIÓN. EN TORNO A LA GAUCHESCA DE GAÚCHOS Y DE GAUCHOS
}

\author{
POR \\ Miriam Gárate \\ Universidade Estadual de Campinas
}

Puestos frente a un espacio cultural cuyos contornos parecen desbordar las fronteras del (los) estado(s) nacional(es) (mas aún, donde ciertas manifestaciones culturales de la región parecen contradecir el orden político-estatal); puestos frente a un espacio cultural cuyos contornos parecen no coincidir, stricto sensu, con jurisdicciones linguísticas (mejor aún, que parece propiciar formas de contacto y contaminación entre las lenguas implicadas); puestos frente a un espacio cultural de ese tipo, cabe preguntarse: ¿cómo se produjeron identidades y alteridades en el seno de ese hábitat en diversas circunstancias históricopolíticas? ¿A través de qué mecanismos se hizo del "prójimo” un "otro” (o del otro un semejante) cuando la coyuntura así lo exigió? ¿En torno a qué símbolos y prácticas culturales se constituyeron esas identidades y alteridades? ¿Y qué sucede cuando los símbolos o prácticas erigidos en emblema son en principio los "mismos” para sujetos adscritos a diferentes estados nacionales? ¿Cómo se resuelve, en tales casos, el problema de las influencias, intercambios, semejanzas? He aquí algunas de las cuestiones con que se depara quien decide acercarse a un espacio cultural fluido como el configurado por la región, ¿pampeana?, ¿rioplatense? ¿platina?, ¿gauchesca?, ¿gaúcha? (la denominación desde luego no es inocua), escenario de constantes repulsiones y atracciones, afinidades y rechazos, entre por lo menos tres estados (Brasil, Uruguay, Argentina) a lo largo de casi dos siglos.

En virtud del foco de interés de este trabajo, del recorte tanto espacial como cronológico (habré de limitarme al área sul-rio-grandense de Brasil y al período comprendido entre mediados del siglo XIX y mediados del XX) otra manera de formular la misma cuestión podría ser ésta: ¿ dónde comienza y dónde termina la gauchesca?; ¿dónde el gaucho se transforma en gaúcho y qué problemática comporta — para quiénes- este "mero" cambio de acentuación? De hecho, aunque escritos por sujetos de distinto origen sociocultural y producidos en diversas épocas, los textos que me propongo comentar a continuación poseen un rasgo en común: el de pensar/dramatizar una posición fronteriza. O quizás habría que decir una posición en la que la frontera hace problema, ya que dependiendo de la coyuntura y de la perspectiva adoptada, ora la frontera se desdibuja, casi se borra, ora se se vuelve a armar. ${ }^{1}$

${ }^{1}$ En Medio siglo de narrativa latinoamericana (1922-1972), más precisamente en el apartado número trece (El caribe es un solo país), Angel Rama afirma: "La existencia de un área literaria caríbica, 
No por obvia la advertencia deja de ser necesaria: las páginas que siguen configuran un primer acercamiento realizado a partir del examen de un corpus representativo. Consecuentemente, ni agotan las cuestiones planteadas, ni formulan conclusiones.

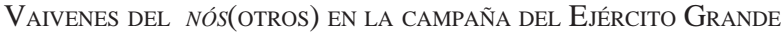

En el Cancioneiro guasca, antología organizada por José Simões Lopes Neto en 1910, que reúne quadras, trovas, poesías históricas y desafíos sul-rio-grandenses, pueden leerse los versos escritos por el capitán Francisco Marques de Oliveira durante la campaña del Ejército Grande, realizada en 1851-2. ${ }^{2}$ Si se los mira o se los piensa en función de sus contenidos políticos más evidentes, los versos forman parte del ciclo gauchesco antirrosista, dado que allí encontramos una serie de lugares comunes (conjunto de epítetos negativos asociados al "tirano", por ejemplo) e inclusive de referencias textuales (a cierta altura se hace mención a A Resvalosa), bien conocidos por argentinos y uruguayos. En primera instancia, pues, la identificación del rival y el ulterior desafío sirven para constituir la voz del gaúcho como soldado antifederal. En primera instancia, pues, la alianza (la extensión del nós delineado por el texto) incluye a todos los que combaten contra el "monstruo":

\author{
Rosas, com sua quadrilha \\ De blancos em Buenos Aires, \\ Dizem que já armou os frailes \\ contra nós. \\ Há de, esse monstro feroz, \\ Experimentar desta feita, \\ Aquilo que o diabo enjeita \\ No inferno. \\ Deus queira que neste inverno \\ O caudilho, degolado, \\ Não vá, de presente, enviado \\ A Satanás!
}

\begin{abstract}
diferenciable dentro de la América Latina, plantea un desafío al comparatismo, pues en ella conviven diversas lenguas (dos, al menos, son románicas, el español y el francés y también dos dialectos, el 'créole' y el papiamento que procede del portugués, amén de las lenguas nórdicas como el inglés y el holandés) que son conductoras de ricas literaturas y se han desarrollado dentro de estructuras sociales parecidas" (195). Guardadas las debidas proporciones y especificidades (en el caso que nos ocupa se trata de sólo dos lenguas pertenecientes, por lo demás, a un tronco común), la existencia de un área literaria gauchesco-gaúcha también plantea un desafío al comparatismo.

${ }^{2}$ Además de un concienzudo recopilador de la poesía popular sul-rio-grandense, Simões Lopes Neto fue el cuentista más interesante del regionalismo gaúcho de las primeras décadas del siglo. Sobre su producción ficcional, puede consultarse el libro de Ligia Chiapini de Moraes Leite, Regionalismo e modernismo: o caso gaúcho. En lo que respecta a la campaña del Ejército Grande, coalición entrerriano-uruguayo-brasileña de la cual el autor de la composición a ser examinada formó parte, la crónica más conocida para los lectores argentinos continúa siendo la publicada, inicialmente en Brasil (1852), por Domingo Faustino Sarmiento, bajo el título de Campaña en el Ejército Grande.
\end{abstract}




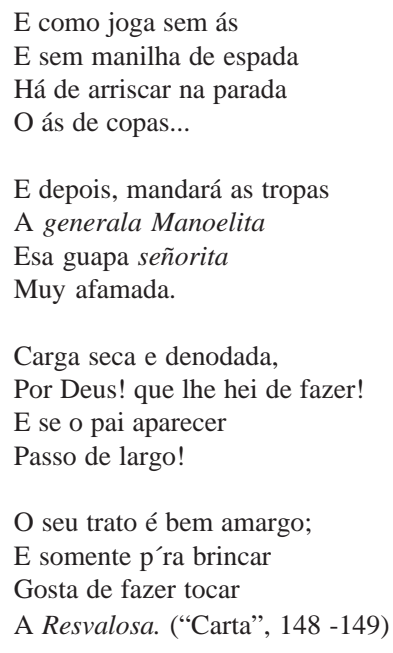

No obstante, si se repara en los versos que preceden a los anteriormente citados, la alianza se trama, por la vertiente del lamento, con todos los gaúchos (¿y por qué no los gauchos?) que vivem (sufren) deste jeito (forma). ${ }^{3}$ Antes de modular la voz del gaúchosoldado antirrosista, el texto modula la voz del gaúcho-soldado padeciendo en campaña:

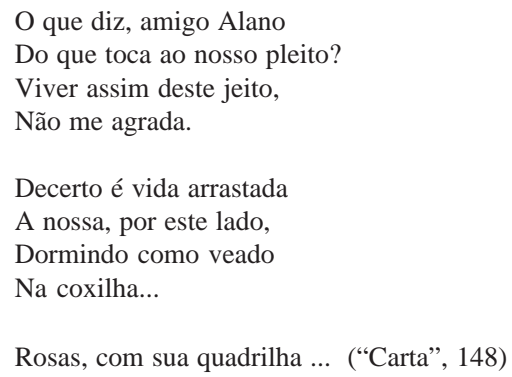

Hasta aquí, dos contenidos atribuibles al nós han diseñado otras tantas cadenas de inclusiones y exclusiones, de semejanzas y diferencias: nós (los enemigos de Rosas) versus los otros (los aliados de la fiera); nós (los que hacemos y soportamos la guerra) versus los otros (los que no viven privaciones ni duermen a campo abierto). Huelga decir que un nós y el otro no se recubren, que sus respectivos significados son potencialmente antagónicos o al menos divergentes. En otras palabras, un nós es belicista y asume como propia la misión de guerrear (habla de la lucha contra Rosas como nosso/nuestro pleito); el otro nós protesta

\footnotetext{
${ }^{3}$ Sobre la noción de "alianza”, así como sobre los “dos tonos” constitutivos del género gauchesco (desafío y lamento) véase el excelente trabajo de Josefina Ludmer, El género gauchesco. Un tratado sobre la patria, en especial, los dos primeros capítulos.
} 
ante la vida arrastada/miserable impuesta por la guerra. Pero, a pesar de la diferencia nada desdeñable entre ambos, tanto en un caso como en el otro los versos son portadores de sentidos que atraviesan la(s) frontera(s) nacional(es), que se proyectan más allá de la lengua en que son proferidos. Y sin embargo, será precisamente por medio de la(s) lengua(s) que el texto habrá de reintroducir la distinción entre el aquí y el allá, el ellos y el nós, nossa terra y este país, dando expresión al anhelo de "la vuelta” al pago:

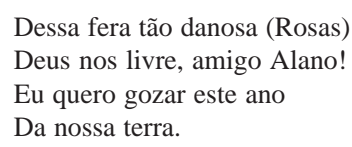

Ao feijão chamam poroto

À batata, cacaraxa

E o que chamamos cachaça

eles dizem-caña. (“Carta”, 149)

Si el antibelicismo de las cuartetas iniciales podía hacerse extensivo a todos los gaúchos-gauchos miserables que sufren en y por la campaña militar, estas cuartetas circunscriben (negativizándolo) el espacio de la guerra a este país. Mejor aún, a este país sempre em guerra, expresión que introduce el breve lamento por la tierra improductiva, lamento también legible, como demostró Josefina Ludmer, en la gauchesca rioplatense; rasgo común al género, en suma. De modo que lo “mismo” (la queja por la tierra donde sólo crecen cardos) se dice acerca de un espacio y desde una posición enunciativa que configura al lugar del cual se habla como diferente de nossa terra y consecuentemente a nós como otros. ${ }^{4}$ Así como se nombra a lo "mismo” con diferentes palabras, porque, “o que chamamos de cachaça/ eles dizem caña”. Llegados a este punto, tendríamos que preguntarnos, como lectores, qué valdría la pena enfatizar o hacer pesar más, si el hecho de que unos y otros comen y beben lo mismo, aunque en un idioma diferente, o la propia diferencialidad (frontera) del idioma; si los tonos y formas poéticas comunes o la distancia implicada, a despecho de la identidad de tonos así como de formas, en el pasaje del portugués al español. En lo que concierne al capitán Marques Moreira no hay duda de que las diferencias pesaron más:

${ }^{4}$ Sintomáticamente, la historiografía brasileña oficial del pasaje de siglo verá en Río Grande do Sul (en el mismo Río Grande do Sul que el estado brasileño movilizó militarmente en función de sus intereses en numerosas oportunidades), un foco de permanentes revueltas y de alzamientos armados amenazadores. Ejemplos paradigmáticos, la revolución farroupilha, pródigamente cantada y poetizada por los gaúchos, y la revolución federalista de 1893. Como mostraré más adelante, a los ojos de la élite carioca, del poder central con sede en Río de Janeiro, los gaúchos son jinetes sempre em guerra. O sea que desde otro lugar se predica lo mismo acerca de los gaúchos, que el gaúcho Marques de Oliveira predica aquí de los gauchos. 


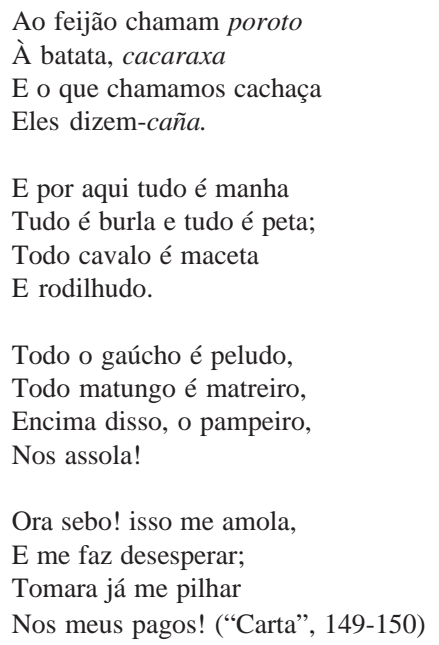

La temporaria indecisión y eventual coextensividad de las primeras estrofas se resuelve en una secuencia de distinciones cuyo signo de valor es innecesario comentar. Aquí, en este país, todo es maña, burla, peta (mentira); aquí, los caballos (apreciados aquí y allá) son petizos, rodilludos, cuando no matreros; aquí, todos los gauchos son desconfiados, irascibles; y encima de eso, el viento pampero. ¿Cómo no desesperar y anhelar la vuelta al pago si todo es parecido pero negativo, familiar pero peor? Tan familiar, inclusive en lo peor de la experiencia padecida, que, de materializar el deseo de pilhar-se já/aparecer súbitamente ya en sus pagos, Marques de Oliveira habría engrosado la fila de gauchos y gaúchos desertores; de los numerosos desertores, de aquí y de allá, cansados de sufrir la guerra.

UN MONUMENTO DISPUTADO

En el 1900, Alcides Maya, reconocido escritor sul-rio-grandense, autor, entre otras obras, de la novela Ruynas vivas (1910), de los volúmenes de cuentos Tapera (1911), Alma bárbara (1922), así como de los ensayos reunidos en O Rio Grande Independente (1898), publica un artículo titulado “O Rio-Grande Mental”. El texto empieza sosteniendo que:

Ao gênio orgulhoso dos helenos repugnava o contato grosseiro dos Macedónios semibárbaros; estes não passavam, a princípio, de hábeis cavaleiros, que uma vaga tradição de descendência permitia aparecessem nos jogos em que se afirmava periodicamente a unidade étnica e moral dos gregos.

O Rio Grande, no Brasil, para os brasileiros, é uma espécie de Macedônia de atraso e de barbarismo. Os helenos requintados que passeiam pela rua do Ouvidor... pensam de nós que... sabemos domar potros (...).

Nas clacificações literárias de poetas e escritores nacionales os rio-grandenses são exluídos por sistema ou por ignorância. (20) 
Distante, bárbaro, extraño, casi extranjero; tal el estatuto de Rio-Grande do Sul a los ojos de los "helenos" cariocas de la Rua do Ouvidor (una especie de calle Florida del Rio de Janeiro pasaje de siglo), según Alcides Maya. Convocada para ser sometida a cuestionamiento, la caracterización, supuestamente circunscrita a lo literario, genera inmediatamente una respuesta/propuesta en la que abundan sin embargo las expresiones de orden político. Si hasta el presente, "por sistema o por ignorancia”, los escritores sul-riograndenses fueron "excluidos" del mapa de las letras nacionales, el tipo de incorporación reivindicada es de índole federativa: "Ao federalismo político, definitivamente triunfante, corresponda o federalismo literário. Evitemos a centralização das letras. O Brasil não pode ser, em estética, uma dependência da Capital Federal” (21), afirma el autor.

Ahora bien, si en una primera instancia el texto formula un doble reclamo de integración y autonomía, de unidad en el derecho a la diferenciación, en un segundo momento, curiosamente, busca hacer de lo "propio” un eventual símbolo de la totalidad. En otras palabras, pasa de la actitud defensiva de quien, sabiéndose en los márgenes y diferente, exige o solicita un espacio, a una actitud ofensiva dada por la proyección y generalización de esa supuesta diferencia específica: “O mestiço mais característico da história americana é o gaúcho. Em nenhuma outra região, a não ser talvez em São Paulo, onde surgiu o mameluco, apareceu uma figura tão soberana e de ação tão decisiva como o monarca das coxilhas rio-grandenses, das solidões pampeanas” (26).

No obstante, la pretensión de elevar al gaúcho a la dignidad de tipo tan representativo como el mameluco paulista lejos de resolver las cosas se diría que reaviva viejas sospechas, sospechas que venían formulándose por lo menos desde la guerra de los farrapos y seguirían formulándose aún en las primeras décadas del siglo: reducto crónico de un “artiguismo” mal disfrazado para Capistrano de Abreu (1900), “corpo estranho na federação brasileira” para José Veríssimo (1912), tierra habitada por "gente platinizada” para Basílio Magalhaes (1914), "platino demais para entrar legitimamente na nacionalidade brasileira” según João Ribeiro; así era visto, en Brasil y por brasileños, Rio Grande do Sul. ${ }^{5}$ Y, de hecho, el ir y venir de las coxilhas/cuchillas rio-grandenses a las solidões pampeanas deja entrever un problema (una eventual in-diferencia) con el que Alcides Maya tendrá que lidiar e intentar resolver. ¿De qué manera? Retornemos una vez más al parágrafo citado:

\begin{abstract}
O mestiço mais característico da história americana é o gaúcho. Em nenhuma outra região, a não ser talvez em São Paulo, onde surgiu o mameluco, apareceu uma figura tão soberana e de ação tão decisiva como o monarca das coxilhas rio-grandenses, das solidões pampeanas. Na Argentina, no Uruguay, o gaúcho viveu e vive ainda, a exemplo do nosso, dextro nas lides campeiras, audaz na guerrilha, revel e independente. Mas lá a sua influição no caráter coletivo não foi tão geral e profunda qual a exercida entre nós. (26)
\end{abstract}

Partir del reconocimiento de lo común a la zona (el gaúcho o gaucho) para instituir de inmediato una relación jerárquica (“a exemplo do nosso”); reforzar esa operación inicial mediante un recurso cuantitativo (acá influyó más que allá): primeros pasos de una estrategia diferenciadora que repetirá, ahora desplazándolos hacia el otro lado de la frontera,

\footnotetext{
5 Para un análisis de esta cuestión desde una perspectiva historiográfica véase Historiografia rio-
} grandense, de Ieda Gutfreind, y también “Nós ‘gaúchos', os separatistas”, de Helga Piccolo. 
los mismos estereotipos que poco antes cuestionara. Para los helenos cariocas, vale decir para el centro político-cultural del Estado Brasileño, los gaúchos son bárbaros, violentos, insubordinados, rebeldes; "gauchos malos", de acuerdo con la tipología sarmientina. Alcides Maya empuja al gaucho malo un poco más allá, se queda con el "gaucho bueno” (con el gaucho patriota, fiel soldado) y lo transforma en arquetipo de Río Grande:

As lutas do gaúcho argentino, as do uruguaio, travaram-se, sim, frequentemente, em defesa do torrão natalício; porém, ambos deixaram-se acaudilhar pelas facções políticas, habituaram-se à luta sem ideal, tornaram-se um agente de dissolução social e a grande obra da política republicana platense foi o extermínio, a guerra sem tréguas, sem descanso, às pandilhas viciadas no saque e na carnificina. No Rio-Grande nunca sucedeu isso; ao contrário, a política imperial, não se falando em 35, nobre movimento lealmente afirmado pelas armas, jamais reconheceu a necessidade de guerrear os habitantes da campanha sulina, contando invariavelmente com eles na defensão do Brasil. Há na História riograndense um certo cunho majestosso, impresso pela atitude do gaúcho. Individualmente, ele era capaz dos maiores rasgos de violência belicosa, das piores aventuras...; coletivamente, no entanto, o seu braço invicto serviu de esteio inabalável à pátria segurança, foi o mantenedor da sociedade que se constituia... Foi o preparador da história, foi o preparador do povo. (27)

Imposible analizar en detalle en un trabajo de las dimensiones de éste los malabarismos realizados por el autor. Baste enunciar, a manera de resumen, algunos interrogantes: ¿por qué los enfrentamientos que se desarrollan del otro lado son "pandillismo", proceso "desagregador", "lucha sin ideal” y la revolución de 1835, en cambio, es "un noble movimiento lealmente afirmado por las armas”? (Noble movimiento del cual sin embargo Alcides Maya prefiere no hablar — “não se falando em 35”-, puesto que se vería en el aprieto de tener que definir la revolución farroupilha — ¿movimiento separatista?, ¿republicano?, ¿ambas cosas? - y de referirse a la represión consumada por el poder central). ${ }^{6}$ Asimismo, ¿por qué los efectos de la lucha armada allá son disolventes mientras

${ }^{6}$ Declarada la independencia del Brasil (1822), se inicia un período de prolongadas disputas entre “radicales” y “conservadores” en torno a la forma de organización político-jurídica más adecuada para la nación. Este proceso conducirá a la abdicación del Emperador Don Pedro I, en 1831, a favor de su hijo, con cinco años de edad en aquel momento. Se abre entonces el no menos agitado período de las Regencias, que culminará a su vez con la aprobación de la "mayoridad" de Don Pedro II, Emperador del Brasil en ejercicio del poder a partir 1840. Bajo las regencias, y especialmente desde 1835, estallan varias revueltas provinciales contra el poder central. Entre ellas se destaca especialmente, por su fuerza y duración, la llamada revolución farroupilha de Río Grande do Sul, donde los estancieros gaúchos proclaman la República de Piratini y resisten a las fuerzas federales durante casi una década. (Más o menos contemporáneamente se dan procesos análogos en Pará, donde los cabanos se declaran en lucha contra las fuerzas legalistas y en Bahia, donde el médico Francisco Sabino intenta sublevar a la población y proclamar la República Baiense, hacia 1837). Al finalizar la década del 30 el período más agudo de la crisis habrá sido superado y el gobierno central retomará el control del país. Las visiones legadas por la producción historiográfica acerca de la revolución farroupilha son contradictorias: movimiento de vocación "separatista", inspiración "artiguista", animado por el designio de constituir una confederación con el Uruguay, Entre Ríos y Corrientes, para unos; "antecedente glorioso de los movimientos republicanos y federalistas" que conducirían a la proclamación de la República Brasileña varias décadas más tarde, para otros (en líneas generales, la interpretación 
que acá son aglutinantes y fundadores? O aún, ¿por qué cuando se trata del allá Maya es capaz referirse sin la menor reserva a los males del "caudillismo", de la lucha entre "facciones” y carnificinas/carnicerías supuestamente extirpadas gracias a la "gesta patriótica” de los gobiernos del Plata, mientras que cuando se trata del aquí omite la más mínima mención a una guerra de facciones bastante más reciente en el tiempo y cercana en el espacio, como la revolución federalista rio-grandense de $1893 ?^{7}$

Desde luego que mi interés no consiste en pensar estas cuestiones en términos de verdad/mentira sino de actitudes, gestos y movimientos interpretativos resultantes de la necesidad de demarcar un límite precisamente donde, al menos en lo que respecta a ciertos habitos, prácticas y producciones culturales, el límite tiende a ser contradicho. ${ }^{8}$ De allí precisamente la veemencia con que prosigue el texto:

de Alcides Maya se inscribe en esta segunda tendencia). La primera perspectiva (la más común hasta los años veinte de este siglo) acentúa el caracter "platino" de la región; la segunda (dominante a partir de los años 20-30) incorpora la revolución farroupilha a los mitos formadores de la nacionalidad brasileña. Para un análisis pormenorizado del cambio de perspectiva producido en el discurso historiográfico, bien como de sus razones, el libro de Ieda Gutfriend ya mencionado resulta de consulta indispensable.

7 Con la caída del Imperio e implantación de la República (1889) se abre un período de inestabilidad política signado por la disputa y ulterior reacomodación de viejos y nuevos grupos de poder, tanto a nivel regional como nacional. En lo que concierne a la revolución o revuelta federalista de Río Grande do Sul, se trata de una auténtica guerra civil ocurrida entre 1893 y 1895, que deja un saldo de aproximadamente 12.000 muertos, sobre una población total de un millón de personas. Los sectores en pugna, liderados por auténticos caudillos provinciales son, por un lado, el Partido Republicano Rio-grandense (de tradición positivista, tendencia dictatorial, comandado por Júlio de Castilhos) y por otro, el Partido Federalista (resultado de una fusión entre ex liberales y conservadores, bajo las órdenes de Silveira Martins). Disputas virulentas en torno a la Constitución Provincial votada en 1891 (obra de Castilhos y que concentraba muchísimo poder en manos del ejecutivo), fraudes electorales en diversas regiones, destituciones masivas de alcaldes e intendentes de la oposición en cada nueva gestión de gobierno, atentados y crímenes violentos (que aumentan sensiblemente durante el segundo semestre de 1892), prepararon el terreno para la guerra que se desató en 1893 debido a una confluencia de crisis local y crisis nacional. En ese año, con apoyo federal y de su máquina partidaria, Castilhos vence las elecciones para gobernador. Es el décimo octavo gobierno de la provincia desde la implantación de la República, en 1889, y la segunda gobernación explícitamente a cargo de Castilhos, ya que varias autoridades anteriores habían sido indicadas y maniobradas por él. A lo largo de ese proceso, muchos federalistas se exilan en el Uruguay o en Argentina (se presume que alrededor de 10.000 personas huyeron al Uruguay entre junio del 92 y febrero del 93); sus propiedades son saqueadas y sus rebaños diezmados. El 2 de febrero de 1893 los federalistas atraviesan la frontera en dirección a Bagé, con el propósito de destituir a Castilhos. En los dos años y medio de duración del conflicto se organizan tres invasiones desde Uruguay, la primera de ellas comandada por Gumercindo Saraiva/Saravia (hermano de Aparicio Saravia, jefe del Partido Blanco uruguayo). Luego de innúmeros y cruentos actos de violencia cometidos tanto por republicanos como por federalistas, los últimos son derrotados. La paz se declara en agosto de 1895 y se concede una amplia amnistía a los sublevados federalistas, con derecho, inclusive, a la reincorporación en las filas del ejército, después de transcurridos dos años.

${ }^{8}$ Para una lectura de esta misma problemática desde desde el lado uruguayo véase el excelente trabajo de María Inés Torres titulado "Los otros/los mismos: periferia y construcción de las identidades nacionales en el Rio de la Plata”. Torres analiza fundamentalmente el papel de la obra de Zorrilla de 


\begin{abstract}
Se quisessem celebrar num monumento os combates seculares que travamos, se desejassem consubstanciar num arquétipo o valor da nacionalidade, se procurassem insculpir em bronze a alma rio-grandense, tal como é, ... deviam erguer na primeira eminência de nossas fronteiras, miniatura da população, uma estátua equestre de gaúcho, sozinho, vigilante de aspecto, olhar voltado para o horizonte distante, e caracterizado de Farrapo, o lutador contra a prepotência do centro que só depôs as armas para lutar contra os inimigos de fora, de longe, de todo o ignoto espaço castellano... (27)
\end{abstract}

De hecho, todo el ensayo de Alcides Maya dramatiza un campo de tensiones y necesidades de difícil resolución: por un lado, la región sul-rio-grandense precisa estrechar lazos político-culturales con el cuerpo del estado nacional del cual forma parte, pero ni desea "confundirse" por completo con ese organismo, ni quiere someterse a la "prepotencia" de su centro. En suma, por un lado, el texto y la región buscan un equilibrio no muy fácil de alcanzar entre unidad y diversidad, integración y autonomía. Por otro, precisa erguir fronteras contra "os inimigos de fora, de longe" (una lejanía que en realidad está muy cerca) "de todo o ignoto (y sin embargo familiar) espaço castelhano". La "estátua equestre de gaúcho" y la literatura a ella asociada ("Imaginai no futuro, conservadas as qualidades peculiares à raça, e dispondo esta de um esplêndido cenário de legendas, onde se move todo um mundo de seletos personagens de bravura, de galhardia, de medievalismo bélico, com usos, vestuarios, imaginai no futuro que opulenta literatura nós teremos” (27)), la estatua y su correspondiente corpus literario, pues, quieren solucionar esta última cuestión. Dependiendo de la perspectiva que se adopte, en lugar de separar y distinguir, subraya zonas de contacto. Como se sabe, hacia la misma época, en Argentina cobra particular impulso el proceso de rehabilitación del corpus gauchesco que habrá de culminar con el ciclo de

San Martín en cuanto agente propulsor de una serie de estrategias discursivas diferenciadoras, tanto con relación al Brasil como a Argentina: "La preocupación por erigir los límites y así construir la diferencia con respecto a los territorios vecinos se hace patente en un fragmento de su conferencia sobre Lavalleja, en la que Zorrilla realiza un verdadero tour-de-force en este sentido: '(Lavalleja) fue el primero que sintió la ley de providencial que decretaba la existencia de una patria independiente en este territorio que bañan el Uruguay, el Plata y el Atlántico; una patria que, siendo subtropical, era al mismo tiempo atlántica. Él fue el primero que vio, con la clarividencia del que cierra fuertemente los ojos para ver, cómo se desprenden los grandes ríos meridionales de las entrañas de América, para venir a desembarcar en el Plata, formando dos regiones distintas, dos patrias, hermanas pero diferentes, a ambos lados de esos ríos. Él comprendió, o más bien dicho, sintió en el fondo de su ser, cómo, por una ley, no sólo sociológica sino también geológica y etnológica, este pedazo de suelo americano tenía que ser el territorio de una patria independiente. Porque si según las leyes sociológicas, estábamos unidos, por la lengua y las tradiciones españolas, a nuestros hermanos de allende el Plata, que tienen por núcleo geológico el levantamiento de los Andes, según las leyes étnicas pertenecíamos a la formación atlántica del Brasil. Y si éstas nos unían etnológicamente a las antiguas posesiones portuguesas, de ellas nos separaban, no sólo las tradiciones de lengua y de costumbres, no sólo la rivalidad secular de los dos pueblos descubridores, sino también nuestra posición geográfica, que nos separa de los dominios del trópico, y nos marca como el núcleo inconmovible de los pueblos atlánticos subtropicales de la América Meridional' (en Conferencias y discursos, tomo II, 114-115)" (250). El esfuerzo de construcción de una diferencia específicamente nacional conducirá a Zorrilla a la formulación del "mito charrúa”, en cuanto símbolo identitario uruguayo. En lugar de disputar el gaucho y la gauchesca para sí, se optará por dar forma a otros emblemas . 
conferencias proferidas por Leopoldo Lugones en 1913, ulteriormente publicadas bajo el título de El Payador (1916). Allí, la poesía gauchesca es elevada al rango de epopeya nacional. El gaucho, para Lugones, es un rapsoda heleno-criollo (retorno de lo "heleno" atribuido, ahora, al habitante de las “soledades pampeanas”); el gaucho es el artífice de la "civilización argentina” (como en el siglo XIX lo fue de la barbarie), mientras que el "bárbaro”, ahora, para Lugones, es la "plebe ultramarina”, "la chusma que nos hace barullo en el zaguán”: el inmigrante.

REVERBERACIONES

Cuatro décadas después de la publicación del artículo de Alcides Maya, la necesidad de establecer distinciones seguirá haciéndose escuchar en un ensayo de Augusto Meyer sobre “Antônio Chimango", poema de Amaro Juvenal aparecido en 1915, considerado un clásico de la literatura gaúcha. ${ }^{9}$ De hecho, el ensayo de Meyer no posee la manifiesta coloratura política ni la belicosidad del de su antecesor, sino que plantea el problema en un registro “específicamente literario”. Desplazamiento que es signo tanto del nuevo tiempo político, marcado por la definitiva integración de la élite gaúcha a la estructura de poder nacional a partir de la revolución de 1930 y la ascensión de Getulio Vargas, como del nuevo tiempo intelectual, inclinado a las lecturas de corte estilístico-filológico. En sintonía con ese horizonte, Meyer destina la segunda mitad de su ensayo al examen del "rigor estructural” de Antônio Chimango, examen realizado a través del cotejo de manuscritos. Pero antes de analizar supresiones, síntesis y cambios, Meyer plantea una cuestión preliminar, la de las fuentes o virtuales influencias. Y es justamente allí que despunta nuevamente la problemática de la relación tradición gaúcha/tradición platina.

Resumidamente: a pesar de reconocer el carácter fuertemente convencional de la producción gauchesca, Augusto Meyer insiste una y otra vez en la “originalidad” (valor) de Antônio Chimango. Sucede que para demostrar la originalidad alegada — para probar que el "rigor estructural" de su objeto de análisis "não se encontra nos outros poemas gauchescos” (220)—, el crítico se ve obligado a comparar y que todos los términos de comparación convocados pertenecen al corpus rioplatense: José Hernández, primero; Hilario Ascasubi, después; Estanislao Del Campo, por último.

\footnotetext{
${ }^{9}$ El texto de Amaro Juvenal (seudónimo de Rubén Barcelos) articula dos niveles compositivos: por un lado, es una sátira violentísima al todopoderoso de Río Grande do Sul, Júlio de Castilhos, y a su lugarteniente, Borges de Medeiro; por otro lado, la sátira política se encuentra enmarcada por lo que Meyer denomina un "poema descriptivo", donde se refieren las faenas y penurias del trabajador rural, particularmente del tropero. Las cinco rondas que integran el poema se inician narrando las peripecias de la tropa en marcha, luego de lo cual, en el momento de descanso, tío Lautério canta-cuenta la biografía amoral de Antônio Chimango (Borges de Medeiros), capataz servil y oportunista del coronel Prates (Júlio de Castilhos), propietario de la Estancia de San Pedro (antiguo nombre de la provincia de Rio grande do Sul). La obra alcanzó una gran popularidad, se folklorizó y fue retomada por otros escritores: en 1927 aparece la Historia de Dom Chimango, de Homero Prates (poema satírico sobre la revolución de 1923); en 1935, es publicada A volta de Antônio Chimango, de Dino Dezidério (seudónimo de Valdemar Correa), crítica feroz al gobierno del gaúcho Getulio Vargas.
} 
Já se tentou aproximar (os comentários de Tio Lautério) dos conselhos de Viscacha em La vuelta de Martín Fierro. Sem razão, a meu ver. Numa literatura de temas necessariamente limitados, cuja modulação será restrita por força das circunstâncias, ocorrem coincidências, fora de qualquer imperativo de imitação literária. Nesse caso, por exemplo, apenas coincide o tom cínico dos conselhos; quanto ao sentido original, não vejo termo de comparação. ( 213)

Em seu estudo “A origem da Poesia Crioula na Sátira Política”, sustenta Manuelito de Ornelas, depois de apontar vagas aproximações episódicas entre Santos Vega e Antônio Chimango: "Na família lírica do pampa americano, podemos agora, sem temores, situar Amaro Juvenal, com seu Antônio Chimango, muito mais próximo de Hilário Ascasubi do que de José Hernández, quer na semelhança impressionante do tema, dos motivos, das personagens, como da própria técnica.

Nem no tema, ou nos motivos, nem nas personagens e muito menos na técnica vejo eu algum parentesco mais próximo; e a não ser nessa inevitável coincidência de alguns traços, que semelhança maior pode haver entre o informe, desporporcionado e indefinido Santos Vega e a sóbria aquitetura de Antônio Chimango, com sua compassada divisão em cinco rondas ... (219)

Resta ainda, para objeto de comparação, o outro poema gauchesco platino mais conhecido: o Fausto, de Estanislau Del Campo. Mas entre Fausto e Antônio Chimango noto apenas uma coincidência: ambos têm exatamente 1278 versos, nem mais nem menos. Dentro dessa medida exata, porém, há folgado espaço para as divergências, que decorrem do prórpio tema. (220)

Más allá del carácter acertado o erróneo de las aproximaciones Martín Fierro/Antônio Chimango, Santos Vega/Antônio Chimango o Fausto/Antônio Chimango, importa subrayar el empeño puesto por Augusto Meyer en alejar de algún modo lo que otros críticos previamente acercaron y que la propia serie por él instituida, a pesar de sus pesares, supone o deja entrever. "Por fuerza de las circunstancias”, "por el carácter limitado del repertorio”, "ocurren inevitables coincidencias" que se prefiere no caracterizar como circulación, préstamo o inclusive coincidencia en el sentido de confluencia en un lugar comun, sino más bien como coincidencia-fatalidad (como encuentro inevitable) o como coincidenciacasualidad (como encuentro fortuito). En otras palabras, como una aproximación que podría no haber ocurrido o que inevitablemente se hubiera dado, pero que en todo caso no marca a uno de sus términos, el gaúcho, posterior en el tiempo y minoritario en la serie literaria diseñada, con el signo de la deuda o influencia exterior. Lo que se repele, en suma, es la aproximación voluntaria que la imitación supondría, la aceptación de un modelo situado más allá del límite patrio. Esto, vale la pena reiterar, aunque todos los parámetros utilizados para medir la originalidad/superiorioridad de Antônio Chimango vengan del “exterior” y, consecuentemente, nieguen o contradigan esa exterioridad. ${ }^{10}$

${ }^{10}$ A pesar de no ser el objetivo de este trabajo efectuar un análisis del poema de Amaro Juvenal/ Rubén Barcelos, quizá la pista para pensar su peculiaridad hoy, a nuestros ojos, radique en el hecho de que Antônio Chimango yuxtapone en una misma composición, y ya a las puertas de nuestro siglo, dos formas/momentos de la literatura gauchesca que la gauchesca rioplatense no llegó a reunir de modo 
Llegados a este punto, tal vez sería oportuno preguntarse nuevamente: ¿dónde comienza y dónde termina la gauchesca?

\section{BiBLIOGRAFÍA}

Gutfreind, Ieda I. Historiografia rio-grandense. Porto Alegre: Ed. da Universidade UFRGS, 1992.

“A historiografia sul-rio-grandense e o mito do gaúcho brasileiro”. Nós, os gaúchos. Porto Alegre: Ed. da Universidade UFRG, 1993.

Leite, Ligia Chiapini de Moraes. Regionalismo e modernismo: o caso gaúcho. São Paulo: Ática, 1978.

Ludmer, Josefina. El género gauchesco. Un tratado sobre la patria. Buenos Aires: Sudamericana, 1988.

Lugones, Leopoldo. El payador. Caracas: Biblioteca Ayacucho, 1991.

Maya, Alcides. "O Rio-Grande Mental”. O ensaio Literário no Rio Grande do Sul (18681960). Teoria Crítica e História Literária. Flavio Loureiro Chaves, org. Rio de Janeiro: INL/MEC, 1979. 20-30.

Meyer, Augusto. “Antônio Chimango”. Prosa dos Pagos. Río de Janeiro: Presença/IMEC, 1943. 207-238.

Neto, José Simões Lopes. Cancioneiro Guasca. $2^{a}$ edición. Rio de Janeiro: Editora Globo, 1962.

Piccolo, Helga. “Nós ‘gaúchos’, os separatistas”. Nós, os gaúchos / 2. Porto Alegre: Ed. da Universidade UFRG, 1994.

Sarmiento, Domingo Faustino. Campaña en el Ejército Grande. Buenos Aires: Universidad Nacional de Quilmes, 1997.

Rama, Angel. "Medio siglo de narrativa latinoamericana (1922-1972)”. La novela en América Latina. panoramas 1920-1980. Procultura S.A./Iinstituto Colombiano de Cultura, 1982. 192-216.

Rodriguez Molas, Ricardo. “Lo gauchesco en el Brasil. El ‘Antonio Chimango”” de Amaro Juvenal”. Universidad. Publicación de la Universidad Nacional del Litoral, 1957. 211 232.

Torres, María Inés. "Los otros/los mismos: periferia y construcción de las identidades nacionales en el Rio de la Plata”. Esplendores y miserias del siglo XIX. Cultura y sociedad en América Latina. Javier Lasarte, Graciela Montaldo, María Julia Daroqui, orgs. Caracas: Monte Avila Editores/ Latinoamericana/Equinoccio/Ediciones de la Universidad Simón Bolivar, 1994. 243-260.

Weinberg, Félix. "La poesía gauchesca de Hidalgo a Ascasubi”. Trayectoria de la poesía gauchesca. Borello, Rodolfo et al. Buenos Aires: Plus Ultra, 1977. 103-145.

Zorrilla de San Martín, J. Conferencias y discursos. 3 Vols. Montevideo: Imprenta Colorada, 1930.

tan visible: el panfleto político (propio del tiempo de Hidalgo o de la gauchesca federal/antifederal), el alegato o denuncia social más amplio sobre las condiciones de existencia del campesino (el tiempo de José Hernández y de su Martín Fierro). 